University of Nebraska - Lincoln

DigitalCommons@University of Nebraska - Lincoln

Faculty Papers and Publications in Animal

Science

Animal Science Department

March 1999

\title{
Genotypic Expression with Different Ages of Dams: III. Weight Traits of Sheep
}

H. Okut

University of Nebraska-Lincoln

C. M. Bromley

University of Nebraska-Lincoln

L. Dale Van Vleck

University of Nebraska-Lincoln, dvan-vleck1@unl.edu

G. D. Snowder

USDA-ARS, U.S. Sheep Experiment Station, Dubois, ID

Follow this and additional works at: https://digitalcommons.unl.edu/animalscifacpub

Part of the Animal Sciences Commons

Okut, H.; Bromley, C. M.; Van Vleck, L. Dale; and Snowder, G. D., "Genotypic Expression with Different Ages of Dams: III. Weight Traits of Sheep" (1999). Faculty Papers and Publications in Animal Science. 282.

https://digitalcommons.unl.edu/animalscifacpub/282

This Article is brought to you for free and open access by the Animal Science Department at DigitalCommons@University of Nebraska - Lincoln. It has been accepted for inclusion in Faculty Papers and Publications in Animal Science by an authorized administrator of DigitalCommons@University of Nebraska - Lincoln. 


\title{
Genotypic Expression with Different Ages of Dams: III. Weight Traits of Sheep ${ }^{1}$
}

\author{
H. Okut*,2, C. M. Bromley*, L. D. Van Vleck ${ }^{\dagger, 3}$, and G. D. Snowder‡ \\ *Department of Animal Science, University of Nebraska, Lincoln 68583-0908; †ARS, \\ USDA, Roman L. Hruska U.S. Meat Animal Research Center, Lincoln 68583-0908; \\ and ¥ARS, USDA, U.S. Sheep Experiment Station, Dubois, ID 83423
}

\begin{abstract}
Correlations between genetic expression in lambs when dams were young ( $1 \mathrm{yr}$ ), middleaged ( 2 and $3 \mathrm{yr}$ ), or older (older than $3 \mathrm{yr}$ ) were estimated with three-trait analyses for weight traits. Weights at birth ( $\mathbf{B W T}$ ) and weaning ( $\mathbf{W} \mathbf{W}$ ) and ADG from birth to weaning were used. Numbers of observations were 7,731, 9,518, 9,512, and 9,201 for Columbia ( COLU), Polypay (POLY), Rambouillet
\end{abstract} (RAMB), and Targhee (TARG) breeds of sheep, respectively. When averaged, relative estimates for WWT and ADG were similar across breeds. Estimates were variable across breeds. On average, direct heritability was greater when environment was young dams (.44 for BWT and .34 for WWT) than when environment was dams of middle age or older (.24 and .28 for BWT and .20 and .16 for WWT, respectively). Maternal heritability was greater when dams were middle-aged or older (.28 and .22 vs .18) for BWT but was greater when dams were younger (.10 vs .05 and
.04) for WWT. The estimates of genetic correlations for direct effects across age of dam environments averaged .32 for birth weight and averaged .70 for weaning weight. Average estimates of maternal genetic correlations across age of dam classes were .36 or less for both BWT and WWT. Average estimates of correlations among maternal permanent environmental effects were .49 or less across age of dam classes. Total maternal effects accounted for .33 to .42 of phenotypic variance for BWT and for .09 to .26 of phenotypic variance for WWT. The average estimates of genetic correlations between expressions of the same genotypes with different ages of dams suggest that measurements of BWT of lambs with dams in young, middle, and older age classes should be considered to be separate traits for genetic evaluation and that for WWT measurements with young age of dam class and combined middle and older age of dam classes should be considered to be separate traits for genetic evaluation.

Key Words: Birth Weight, Weaning Weight, Genotypes

@1999 American Society of Animal Science All rights reserved.

J. Anim. Sci. 1999. 77:2372-2378

\section{Introduction}

Accurate estimates of genetic parameters that describe the population being evaluated are essential for making selection progress. Genetic parameters for weight traits are usually estimated by simply adjusting for nongenetic effects including age of dam. Results from previous studies (Maria et al., 1993; Tosh and Kemp, 1994; Al-Shorepy and Notter, 1996; Näsholm and Danell, 1996; van Zyl, 1998) have shown that estimates of direct heritability for weight

\footnotetext{
1Published as paper no. 12434, J ournal Ser., Nebraska Agric. Res. Div., Univ. of Nebraska, Lincoln 68583-0908. Partial support of the senior author by NATO Science Fellowship Programmed by the Scientific and Technical Research Council (TUBITAK) of Turkey.

${ }^{2}$ Current address: Faculty of Agriculture, Yuzuncu Yil Universitesi Ziraat Fakultesi, 65080 Van Turkey.
}

traits early in life have ranged from .00 to .56 , of maternal heritability from .00 to .29 , and of genetic correlation between direct and maternal genetic effects from -.99 to .99 . Whether more progress can be made in a selection program by considering the age of the dam as part of the trait (Falconer, 1952), rather than in the usual way by adjusting for age of dam, has not been studied. The objective of this study was to estimate parameters necessary to determine for weight traits whether age of the dam should be considered as a part of the trait for genetic evaluation.

\footnotetext{
${ }^{3}$ To whom correspondence should be addressed: A218 Animal Sciences, Univ. of Nebraska, Lincoln 68583-0908 (phone: 402/ 472-6010; fax: 402/472-6362).

Received October 26, 1998.

Accepted March 31, 1999.
} 


\section{Materials and Methods}

Data were from the United States Sheep Experiment Station, Dubois, ID, for the period 1974 through 1996 for Columbia, Polypay, Rambouillet, and Targhee breeds. Basic statistics of the data are shown in Table 1. Ercanbrack and Knight (1998) have provided a summary of management conditions.

Weight traits for this study were individual birth weight (BWT), ADG, and individual weaning weight ( WWT). Average daily gain was calculated as the difference in weight between WWT and BWT and divided by age in days at weaning. I ndividual weaning weight was adjusted to $120 \mathrm{~d}$ of age using birth weight and average daily gain from birth to weaning. Thus, individual $W W T=B W T+(120 \times A D G)$. The few outliers that were greater than or less than 4.5 unadjusted phenotypic standard deviations from the overall mean for the breed for a trait were deleted from data sets before analysis to reduce possible influence on estimates of variance. The data were previously analyzed by van Zyl (1998), who estimated genetic parameters among and between groups of prolificacy, weight, and wool traits.

Initially, the data for each trait within each of the four breeds were split into 10 files by year of age of dam. For the 40 data sets created, 120 single-trait analyses ( 4 breeds $\times 10$ age groups $\times 3$ traits) were performed. Preliminary analyses indicated for all breeds that estimation of variance components was not practical for most age groups because of small numbers of observations. Therefore, the data were divided into files by three age of dam classes: young age ( $1 \mathrm{yr}$ ), middle ages ( 2 and $3 \mathrm{yr}$ ), and older ages (older than $3 \mathrm{yr}$ ). Then, a total of 48 single-trait analyses ( 4 breeds $\times 3$ age groups $\times 4$ traits) were performed to obtain starting values for three-trait analyses, which are also reported for comparison. Three-trait analyses were done with the measurement for a trait on a lamb assigned to one of the three age of dam classes when the lamb was born. A ewe could have at most one lambing at the young age and two lambings in the middle age class. All pedigree information from 1974 to 1996 was used.

\section{Statistical Analysis}

The basic procedures of the analyses were performed as in the first two articles of this sequence (Okut et al., 1999a,b), with three main differences. Single-trait analyses did not suggest dropping maternal genetic effects from the model. Age classes were by ages of ewes at birth of the lambs with records, rather than by age of ewe on which measurements were taken (prolificacy and wool traits). The permanent environmental effect in the model was for the dam's maternal permanent environmental effect rather than a direct permanent environmental effect on the animal being measured.

Sex of lamb, age of dam (only for middle and old ages), band $\times$ year, and type of birth-rearing combina- tion were fixed factors. Type of birth and rearing code combination were assigned to each lamb to account for a lamb born as a single, twin, triplet, or quadruplet and for being reared by its own or by a foster dam (van Zyl, 1998). Direct genetic, maternal genetic, maternal permanent environmental, and residual were random effects.

The same linear animal model was used for all traits, except that the permanent environmental effect of the dam was not included for the single-trait analyses of progeny of young ewes:

$$
\mathbf{y}=\mathbf{X} \boldsymbol{\beta}+\mathbf{Z}_{\mathrm{a}} \mathbf{u}_{\mathrm{a}}+\mathbf{Z}_{\mathrm{d}} \mathbf{u}_{\mathrm{d}}+\mathbf{P} \mathbf{u}_{\mathrm{pe}}+\mathbf{e}
$$

where $\mathbf{y}$ is the vector of observations, $\beta$ is the vector of unknown fixed effects, $\mathbf{u}_{a}$ is the vector of direct genetic effects, $\mathbf{u}_{\mathrm{d}}$ is the vector of maternal genetic effects, and $\mathbf{u}_{\mathrm{pe}}$ is the vector of maternal permanent environmental effects with association matrices $\mathbf{X}, \mathbf{Z}_{a}, \mathbf{Z}_{d}$, and $\mathbf{P}$, respectively, and $\mathbf{e}$ is a vector of random residual effects. The mean vector is $\mathbf{E}(\mathrm{y})=\mathbf{X} \boldsymbol{\beta}$ and

$$
\mathrm{V}\left(\begin{array}{c}
\mathbf{u}_{\mathrm{a}} \\
\mathbf{u}_{\mathrm{d}} \\
\mathbf{u}_{\mathrm{pe}} \\
\mathbf{e}
\end{array}\right)=\left(\begin{array}{llll}
\mathbf{A} \sigma_{\mathrm{a}}^{2} & \mathbf{A} \sigma_{\mathrm{ad}} & 0 & 0 \\
\mathbf{A} \sigma_{\mathrm{ad}} & \mathbf{A} \sigma_{\mathrm{d}}^{2} & 0 & 0 \\
0 & 0 & \mathbf{I}_{\mathrm{pe}} \sigma_{\mathrm{pe}}^{2} & 0 \\
0 & 0 & 0 & \mathbf{I}_{\mathrm{n}} \sigma_{\mathrm{e}}^{2}
\end{array}\right)
$$

where $\mathbf{A}$ is the numerator relationship matrix among animals; $\mathbf{I}_{\text {pe }}$ and $\mathbf{I}_{\mathrm{n}}$ are appropriate identity matrices; and $\sigma_{\mathrm{a}}^{2}, \sigma_{\mathrm{d}}^{2}, \sigma_{\mathrm{pe}^{\prime}}^{2}$ and $\sigma_{\mathrm{e}}^{2}$ are variances due to direct genetic, maternal genetic, maternal permanent environmental, and residual effects, respectively, and $\sigma_{\mathrm{ad}}$ is covariance between direct and maternal genetic effects.

When records of lambs in each of three age groups of dams (young, middle, and older) were considered to be different traits, the analysis was with a three-trait animal model, and the same fixed and random effects as were included in the single-trait analyses were considered for the three-trait models. The genetic covariance matrix for the three direct and three maternal genetic effects was a $6 \times 6$ matrix. Similarly, the variance of maternal permanent environmental effects was a $3 \times 3$ matrix with non-zero covariances. The variance-covariance matrix of residual effects was diagonal with elements $\sigma_{\mathrm{ey}}^{2}, \sigma_{\mathrm{em}}^{2}$ or $\sigma_{\mathrm{eO}}^{2}$ depending on age of dam. Environmental covariances between progeny of the same ewe at different ages were forced into the covariances between maternal permanent environmental effects.

As described in the first article of this sequence (Okut et al., 1999a), although environmental covariance due to dams across age classes can be forced into the maternal permanent environmental effects, interpretation requires some care when the young age of dam class cannot have repeated measures. Because of the complete confounding for that age of dam class between the maternal permanent environmental and residual effects, variance due to those effects can go to 
either component of variance, and this also makes interpretation of the correlations among maternal permanent environmental effects difficult.

An overall environmental correlation, however, can be computed as in the following equation for the environmental correlation between measures in the young $(\mathrm{y})$ and middle $(\mathrm{m})$ age of dam classes:

$$
\begin{gathered}
r_{e_{y m}}=\left[r_{p e_{y m}}\left(p e_{y}^{2} \times p e_{m}^{2}\right) \cdot 5\right] \div \\
{\left[\left(p e_{y}^{2}+e_{y}^{2}\right)\left(p e_{m}^{2}+e_{m}^{2}\right)\right] \cdot 5}
\end{gathered}
$$

where $r_{\mathrm{pe}_{\mathrm{ym}}}$ is the correlation between maternal permanent environmental effects, $\mathrm{pe}_{\mathrm{y}}^{2}$ and $\mathrm{pe}_{\mathrm{m}}^{2}$ are fractions of variance due to permanent environmental effects, and $\mathrm{e}_{\mathrm{y}}^{2}$ and $\mathrm{e}_{\mathrm{m}}^{2}$ are fractions of variance due to residual effects for the young and middle age of dam classes.

Estimates of variance components by REML were obtained using a derivative-free algorithm (Smith and Graser, 1986; Graser et al., 1987) with the MTDFREML program (Boldman et al., 1993). Convergence was considered to have been obtained when the variance of the $-2 \log$ likelihoods in the simplex was less than $1 \times 10^{-6}$. Restarts were performed to confirm global convergence.

\section{Results and Discussion}

\section{Single-Trait Analyses}

Estimates of relative variances and phenotypic variances from singletrait analyses for weight traits with different ages of dams are shown in Table 2.

The range of direct heritability estimates for BWT across breeds and ages is so great that the patterns for individual breeds seem to have little meaning. On average, heritability for lambs with young dams (.30) was greater than for lambs with dams of middle (.22) and older (.24) ages. Average maternal heritability was .14 for lambs with young dams and was half as large as the average estimate of direct heritability. Average estimates of maternal heritabilities were the same (.22) for lambs with middle and older ages of dams and on average were similar to estimates of direct heritability. The estimates of direct-maternal genetic correlations were so varied that any difference for the young age of dam class compared with the others could not be determined. About one-half of estimates were negative (7) and one-half were positive (5), so the average was near zero $(-.03)$. Estimates of relative variance due to maternal permanent environmental effects were similar for all breeds for the middle and older age of dam classes, averaging about .12.

For WWT, direct heritability estimates on average across breeds were similar for the three age of dam classes, although they were somewhat greater for the young age of dam class $(.25, .17$, and .22 for young, middle, and older age of dam classes). In all cases, maternal heritability, on average, was considerably less than direct heritability, averaging $.09, .06$, and .03 for the young, middle, and older age of dam classes, although the estimate of .30 for Rambouillet explains the larger average for the young age of dam class. Generally, maternal heritability estimates for this trait were smaller than for BWT. Notter (1998) reported heritability estimates for $90-d$ WWT of .07 for Polypay and .21 for Suffolk with maternal heritabilities of .00 and .00. In this study, the estimates of genetic correlations between direct and maternal effects were variable, approximately one-half positive (5) and one-half negative (7). The two extreme estimates of 1.00 contributed to an average direct with maternal genetic correlation of .11. Proportions of variance due to maternal permanent environmental effects of dam on average seemed to be less for the middle age of dam analyses than for older age of dam analyses (.05 vs .10 for middle and older age classes, respectively). Total maternal variance accounted for approximately the same average estimate of fraction of total variance (.12 vs .13) for middle and older age classes. Notter (1998) reported total maternal variance for $90 \mathrm{~d}$ WWT to be .23 for Polypay and .19 for Suffolk. From analysis of 90-d WWT as a single trait, Notter and Hough (1997) obtained a zero estimate of heritability for Targhee sheep under range conditions, with maternal effects accounting for .19 of phenotypic variance.

Estimates of direct heritability for ADG were quite variable both among breeds and among age of dam classes within breeds. For ADG, estimates of direct heritabilities ranged from .02 to .71 and of maternal heritabilities from .00 to .35 . Estimates for the young age of dam classes were most variable and generally were based on few records. The estimates of direct heritability averaged across breeds by increasing age of dam class for ADG were .31, .17, and .12, and were generally similar to those for WWT. The high estimate for both WWT and ADG for Rambouillet for the young age of dam class may have inflated the averages for the young age of dam class for both WWT and ADG. Average estimates of maternal heritability for middle and older age of dam classes were small and similar for ADG (.04 and .05) and for WWT (.06 and .03). The estimates of maternal heritability were generally larger for the young age of dam class than for the middle and older age of dam classes. Estimates of genetic correlation between direct and maternal effects for ADG varied among breeds and age of dam classes; some estimates were positive and the others were negative. Estimates of proportional variances due to maternal permanent environmental effects were small and averaged less than those for WWT.

These estimates of heritability for BWT, WWT, and ADG are generally within the ranges of previous estimates for analyses across all ages as a single trait (Maria et al., 1993; Tosh and Kemp, 1994; Al-Shorepy 
Table 1. Numbers of measurements (n) and number of dams (d) with unadjusted means and standard deviations (SD) by breed and age of dam class for individual birth weight, weaning weight, and average daily gain

\begin{tabular}{|c|c|c|c|c|c|c|c|c|}
\hline \multirow[b]{2}{*}{ Breed and age group } & \multirow[b]{2}{*}{$\mathrm{n}$} & \multirow[b]{2}{*}{ d } & \multicolumn{2}{|c|}{ Birth weight, $\mathrm{kg}$} & \multicolumn{2}{|c|}{ Weaning weight, $\mathrm{kg}$} & \multicolumn{2}{|c|}{ Average daily gain, $g$} \\
\hline & & & Mean & SD & Mean & SD & Mean & SD \\
\hline \multicolumn{9}{|l|}{ Columbia } \\
\hline Young & 391 & 364 & 4.49 & .92 & 34.07 & 6.53 & 246.47 & 51.25 \\
\hline Middle & 3,749 & 1,844 & 4.94 & .90 & 36.44 & 6.95 & 262.50 & 54.34 \\
\hline Older & 3,591 & 1,067 & 5.12 & .87 & 36.73 & 6.69 & 263.40 & 52.66 \\
\hline \multicolumn{9}{|l|}{ Polypay } \\
\hline Young & 1,709 & 1,351 & 3.75 & .80 & 34.65 & 6.20 & 240.80 & 48.28 \\
\hline Middle & 4,167 & 1,605 & 4.04 & .75 & 33.64 & 5.83 & 246.66 & 45.72 \\
\hline Older & 3,642 & 920 & 4.20 & .77 & 34.18 & 5.93 & 249.82 & 46.43 \\
\hline \multicolumn{9}{|l|}{ Rambouillet } \\
\hline Young & 615 & 566 & 4.39 & .74 & 32.30 & 5.79 & 232.66 & 45.90 \\
\hline Middle & 3,999 & 1,978 & 4.65 & .78 & 32.55 & 5.75 & 232.48 & 45.01 \\
\hline Older & 4,898 & 1,437 & 4.80 & .76 & 32.89 & 5.74 & 234.10 & 45.34 \\
\hline \multicolumn{9}{|l|}{ Targhee } \\
\hline Young & 418 & 397 & 4.60 & .82 & 31.80 & 6.29 & 226.64 & 49.79 \\
\hline Middle & 4,347 & 2,214 & 4.90 & .88 & 33.79 & 6.82 & 240.66 & 53.19 \\
\hline Older & 4,536 & 1,355 & 5.02 & .84 & 34.08 & 6.64 & 242.08 & 52.41 \\
\hline
\end{tabular}

and Notter, 1995, 1996; Fogarty, 1995). The maternal heritability estimates obtained for ADG and WWT are within the ranges of previous studies (Maria et al., 1993; Al-Shorepy and Notter, 1996; Näsholm and Danell, 1996).

\section{Multiple-Trait Analyses}

Estimates of relative variances and correlations from the three-trait analyses are shown in Table 3. Estimates of direct heritability, maternal heritability, and genetic correlations between direct and maternal effects for BWT, ADG, and WWT differed somewhat between single and three-trait analyses, as well as between breeds and age of dam classes. Estimates of direct heritability from three-trait analyses were generally somewhat larger than those from singletrait analyses. Maternal genetic heritabilities from single and three-trait analyses were somewhat different for young ages but agreed well for middle and older age of dam classes. The greatest differences between single and three-trait analyses were for estimates of genetic correlations between direct and maternal effects, both in sign and magnitude. Many studies have reported that genetic parameter estimates for the same data with single- and multipletrait analyses sometimes are different ( $\mathrm{L}$ in and Lee, 1986; Buttazzoni and Mao, 1989; Keeton et al., 1996; Satoh et al., 1997). However, the inconsistency of estimates between single and multivariate analyses from this study for some breeds are not as large as those from the studies cited above, although most of those studies did not allow missing observations. Satoh et al. (1997) noted that multivariate analysis uses phenotypic information on all traits, whereas univariate analysis does not. As a consequence, multivariate analyses should yield better estimates of variance and covariance components than univariate analyses. In this study, only pedigree information of the age of class of ewes being considered was used in single-trait analyses. In the multiple-trait analyses, however, pooled pedigree information was used. Thus, for the young age of dam class for Polypay, for example, pedigree information on 1,709 animals was used in the single-trait analysis, whereas for multipletrait analyses pedigree information on 9,518 animals was used as well as records from additional relatives for the other two age of dam classes.

A standard for measuring the importance of a genotype $\times$ environmental interaction is Robertson's (1959) suggestion that genetic correlations between environments greater than .80 probably indicate that a genotype $\times$ environment interaction would not be of concern in selection. That guideline will be used in the following discussion.

For BWT, the estimates of direct genetic correlations between age classes were quite variable across breeds, especially for Columbia and Polypay. Estimates of maternal genetic correlations between age classes were also variable, but they were generally smaller than direct genetic correlations when averaged across breeds. For BWT, direct genetic correlations averaged across breeds between age classes were less than expected; the largest correlation (.50) was between middle and older age of dam classes, from an average of .06, .33, .68, and .92. Average maternal genetic correlations were even smaller than direct genetic correlations; the largest correlation (.36) was between middle and older age of dam classes, with a wide range across breeds (.00, .00, .54, and .92). Estimates of genetic correlation between direct and maternal effects in the same age classes also were variable, although more estimates were negative than positive. 
For WWT, all of the estimates of the direct genetic correlation between the middle and older ages of dams for all breeds were greater than .80 (ranged from .82 to unity), with an average of .95. Estimates of direct genetic correlation between young and older age groups were less than .80 (except for Targhee, .85) and averaged .67. Estimates of direct genetic correlation between young and middle age of dam classes averaged only .47. The maternal genetic correlation between middle and older age of dam classes for Polypay was .99, but all other estimates were close to zero, ranging from -.21 to .14. Most estimates of direct with maternal genetic correlations within an age class were small and, on average, negative: -.28 for young, -.02 for middle, and -.02 for older age of dam classes.

Table 2. Estimates of fractions ${ }^{\mathrm{a}}$ of total variance for Columbia, Polypay,

Rambouillet, and Targhee breeds for weight traits with single-trait analyses

\begin{tabular}{|c|c|c|c|c|c|c|}
\hline Trait, age of dam, and breed & $\mathrm{h}_{\mathrm{a}}^{2}$ & $\mathrm{~h}_{\mathrm{m}}^{2}$ & $\mathrm{r}_{\mathrm{am}}$ & $\mathrm{pe}^{2}$ & $e^{2}$ & $\sigma_{\mathrm{p}}^{2}$ \\
\hline \multicolumn{7}{|l|}{ Birth wt, kg } \\
\hline Columbia & .08 & .00 & -.99 & - & .93 & .65 \\
\hline Polypay & .46 & .25 & -.29 & - & .29 & .42 \\
\hline Rambouillet & .39 & .29 & -.12 & - & .32 & .32 \\
\hline Targhee & .29 & .02 & .99 & - & .68 & .47 \\
\hline \multicolumn{7}{|l|}{ Middle } \\
\hline Columbia & .25 & .27 & -.07 & .08 & .42 & .55 \\
\hline Polypay & .14 & .22 & -.17 & .19 & .48 & .39 \\
\hline Rambouillet & .18 & .23 & .08 & .10 & .48 & .41 \\
\hline Targhee & .30 & .18 & .19 & .14 & .34 & .54 \\
\hline \multicolumn{7}{|l|}{ Older } \\
\hline Columbia & .23 & .26 & -.39 & .16 & .45 & .57 \\
\hline Polypay & .14 & .22 & .33 & .09 & .50 & .44 \\
\hline Rambouillet & .22 & .17 & .16 & .11 & .47 & .41 \\
\hline Targhee & .35 & .22 & -.07 & .10 & .35 & .51 \\
\hline \multicolumn{7}{|l|}{ Weaning wt, kg } \\
\hline \multicolumn{7}{|l|}{ Young } \\
\hline Columbia & .00 & .00 & -.69 & - & 1.00 & 26.9 \\
\hline Polypay & .29 & .07 & .00 & - & .64 & 21.8 \\
\hline Rambouillet & .50 & .30 & -.01 & - & .20 & 22.3 \\
\hline Targhee & .23 & .00 & -.18 & - & .77 & 26.6 \\
\hline \multicolumn{7}{|l|}{ Middle } \\
\hline Columbia & .08 & .04 & 1.00 & .09 & .73 & 25.0 \\
\hline Polypay & .11 & .02 & .08 & .08 & .79 & 20.2 \\
\hline Rambouillet & .25 & .13 & -.14 & .00 & .64 & 18.8 \\
\hline Targhee & .28 & .06 & -.01 & .05 & .61 & 26.6 \\
\hline \multicolumn{7}{|l|}{ Older } \\
\hline Columbia & .36 & .08 & .38 & .01 & .49 & 33.0 \\
\hline Polypay & .16 & .02 & -.01 & .12 & .71 & 23.9 \\
\hline Rambouillet & .12 & .02 & 1.00 & .11 & .71 & 20.7 \\
\hline Targhee & .23 & .00 & -.05 & .17 & .60 & 27.6 \\
\hline \multicolumn{7}{|l|}{ ADG, $\mathrm{g}$} \\
\hline \multicolumn{7}{|l|}{ Young } \\
\hline Columbia & .08 & .35 & -1.00 & - & .74 & 1,728 \\
\hline Polypay & .25 & .16 & -.16 & - & .62 & 1,332 \\
\hline Rambouillet & .71 & .29 & .01 & - & .00 & 1,448 \\
\hline Targhee & .21 & .03 & .31 & - & .73 & 1,703 \\
\hline \multicolumn{7}{|l|}{ Middle } \\
\hline Columbia & .09 & .04 & .07 & .01 & .87 & 1,518 \\
\hline Polypay & .09 & .00 & 1.00 & .05 & .83 & 1,262 \\
\hline Rambouillet & .26 & .12 & -.18 & .00 & .67 & 1,187 \\
\hline Targhee & .24 & .02 & .29 & .06 & .66 & 1,663 \\
\hline \multicolumn{7}{|l|}{ Older } \\
\hline Columbia & .02 & .03 & .19 & .13 & .81 & 1,759 \\
\hline Polypay & .14 & .00 & .63 & .10 & .74 & 1,492 \\
\hline Rambouillet & .10 & .13 & .30 & .00 & .74 & 1,330 \\
\hline Targhee & .23 & .04 & -.40 & .15 & .62 & 1,770 \\
\hline
\end{tabular}

${ }^{a} h_{a}^{2}$, direct genetic heritability; $h_{m}^{2}$, maternal genetic heritability; $r_{a m}$, direct-maternal genetic correlation; $\mathrm{pe}^{2}$, variance of permanent environmental effects of dams as fraction of total variance; $\mathrm{e}^{2}$, variance of residual effects as fraction of total variance; and $\sigma_{p}^{2}$, phenotypic variance. 
Estimates of direct genetic correlation between pairs of age of dam classes were also variable for ADG. Estimates averaged over breeds between young and middle, young and older, and middle and older age of dam classes were .41, .70, and .80, respectively. Estimates of maternal genetic correlations between pairs of age of dam classes for ADG were all positive and ranged from .00 to unity and averaged only .24, .42 , and .39 for young with middle, young with older, and middle with older age of dam classes. Estimates of genetic correlations between direct and maternal effects within an age class were small on average,

Table 3. Estimates of correlations and variance components as fractions of total variances for Columbia (C), Polypay (P), Rambouillet (R), and Targhee (T) breeds for weight traits with three-trait analyses ${ }^{\mathrm{a}}$

\begin{tabular}{|c|c|c|c|c|c|c|c|c|c|c|c|c|}
\hline \multirow[b]{2}{*}{ Parameter } & \multicolumn{4}{|c|}{ Birth weight, $\mathrm{kg}$} & \multicolumn{4}{|c|}{ Weaning weight, $\mathrm{kg}$} & \multicolumn{4}{|c|}{ Average daily gain, g/d } \\
\hline & C & $\mathrm{P}$ & $\mathrm{R}$ & $\mathrm{T}$ & $\mathrm{C}$ & $P$ & $\mathrm{R}$ & $\mathrm{T}$ & $\mathrm{C}$ & $P$ & $\mathrm{R}$ & $\mathrm{T}$ \\
\hline$h_{a y}^{2}$ & .37 & .56 & .48 & .35 & .00 & .35 & .79 & .24 & .01 & .31 & .83 & .22 \\
\hline $\mathrm{h}_{\mathrm{am}}^{2}$ & .25 & .21 & .31 & .20 & .13 & .20 & .24 & .25 & .09 & .15 & .23 & .17 \\
\hline $\mathrm{h}_{\mathrm{ao}}^{2}$ & .30 & .19 & .21 & .41 & .04 & .21 & .16 & .22 & .04 & .19 & .11 & .20 \\
\hline$r_{\text {aym }}$ & .21 & .39 & .40 & .53 & -.16 & 1.00 & .34 & .71 & .49 & .68 & .48 & .00 \\
\hline$r_{\text {ayo }}$ & -.51 & .01 & .38 & .48 & .79 & .50 & .54 & .85 & .89 & .54 & .50 & .88 \\
\hline$r_{\text {amo }}$ & .06 & .33 & .68 & .92 & .82 & .99 & 1.00 & 1.00 & .75 & .98 & .51 & .97 \\
\hline $\mathrm{h}_{\mathrm{my}}^{2}$ & .05 & .26 & .23 & .19 & .01 & .09 & .08 & .23 & .09 & .14 & .07 & .20 \\
\hline $\mathrm{h}_{\mathrm{mm}}^{2}$ & .35 & .26 & .32 & .20 & .03 & .04 & .09 & .05 & .03 & .02 & .08 & .05 \\
\hline $\mathrm{h}_{\mathrm{mo}}^{2}$ & .22 & .28 & .20 & .20 & .04 & .06 & .02 & .03 & .06 & .03 & .05 & .02 \\
\hline$r_{\text {mym }}$ & .04 & -.01 & .00 & .61 & -.21 & .14 & .00 & .00 & .70 & .24 & .01 & .00 \\
\hline$r_{\text {myo }}$ & .18 & -.03 & .00 & .00 & .00 & .09 & .00 & .00 & 1.00 & .68 & .00 & .00 \\
\hline$r_{\mathrm{mmo}}$ & .54 & .00 & .00 & .92 & .00 & .99 & .00 & .00 & .98 & .16 & .00 & .42 \\
\hline$r_{\text {aymy }}$ & .05 & -.25 & -.10 & .28 & -.76 & .00 & -.02 & -.35 & -.05 & -.29 & -.20 & -.42 \\
\hline$r_{\text {aymm }}$ & .94 & .63 & .08 & .09 & .08 & .00 & .00 & .00 & .00 & -.05 & .32 & .89 \\
\hline$r_{\text {aymo }}$ & .97 & .28 & .08 & .00 & .01 & .06 & .00 & .14 & -.03 & -.30 & .27 & .20 \\
\hline$r_{\text {ammy }}$ & -.11 & -.10 & .19 & -.02 & -.09 & -.01 & .00 & .00 & .41 & .48 & -.04 & .18 \\
\hline$r_{\text {ammm }}$ & -.31 & -.27 & .11 & .00 & -.11 & .05 & .03 & -.04 & -.16 & .17 & -.16 & .36 \\
\hline$r_{\text {ammo }}$ & -.12 & .51 & .08 & -.01 & .53 & -.04 & .00 & .00 & .08 & .01 & .89 & -.02 \\
\hline$r_{\text {aomy }}$ & .74 & .62 & .10 & .79 & -.02 & -.01 & .03 & -.25 & -.48 & -.16 & .05 & -.31 \\
\hline$r_{\text {aomm }}$ & .64 & .65 & .06 & .23 & .01 & .07 & .00 & .00 & .05 & .04 & .74 & .52 \\
\hline$r_{\text {aomo }}$ & .16 & -.23 & .06 & -.11 & .03 & -.08 & -.02 & -.03 & -.21 & -.14 & .66 & -.02 \\
\hline $\mathrm{pe}_{y}^{2}$ & .34 & .16 & .32 & .15 & .44 & .08 & .13 & .00 & .32 & .10 & .10 & .01 \\
\hline $\mathrm{pe}_{\mathrm{m}}^{2}$ & .09 & .09 & .06 & .15 & .03 & .05 & .01 & .06 & .05 & .03 & .01 & .02 \\
\hline $\mathrm{pe}_{\mathrm{o}}^{2}$ & .13 & .19 & .10 & .11 & .13 & .06 & .11 & .14 & .12 & .08 & .07 & .12 \\
\hline$r_{\text {eym }}$ & .09 & .20 & .00 & .19 & .12 & .10 & .00 & .00 & .14 & .07 & .04 & -.01 \\
\hline$r_{\text {eyo }}$ & .03 & .24 & .00 & .00 & -.03 & .02 & .00 & .00 & .00 & .10 & .00 & .03 \\
\hline$r_{\text {emo }}$ & .06 & .13 & .00 & .06 & .00 & .04 & .00 & .00 & .09 & .01 & .04 & .04 \\
\hline$e_{y}^{2}$ & .24 & .14 & .00 & .32 & .56 & .47 & .00 & .63 & .58 & .50 & .00 & .67 \\
\hline$e_{m}^{2}$ & .40 & .45 & .25 & .42 & .82 & .72 & .65 & .65 & .85 & .79 & .67 & .73 \\
\hline$e_{o}^{2}$ & .40 & .49 & .49 & .33 & .78 & .66 & .71 & .63 & .80 & .72 & .72 & .65 \\
\hline$\sigma_{y}^{2}$ & .65 & .44 & .35 & .47 & 26.88 & 22.44 & 22.74 & 26.62 & 1,730 & 1,281 & 1,389 & 1,673 \\
\hline$\sigma_{\mathrm{m}}^{2}$ & .58 & .39 & .41 & .53 & 24.44 & 20.68 & 18.74 & 25.82 & 1,522 & 1,281 & 1,180 & 1,517 \\
\hline$\sigma_{\mathrm{O}}^{2}$ & .60 & .42 & .41 & .51 & 28.14 & 24.43 & 20.08 & 26.87 & 1,786 & 1,502 & 1,327 & 1,727 \\
\hline
\end{tabular}

$a \mathrm{~h}_{\mathrm{ai}}^{2}=$ direct genetic heritability for age of dam class $\mathrm{i}$ (age of dam classes are: $\mathrm{y}=$ young, $\mathrm{m}=$ middle, and $\mathrm{o}=\mathrm{older}$ ages); $\mathrm{r}_{\mathrm{aij}}=$ direct genetic correlation between age classes $\mathrm{i}$ and $\mathrm{j} ; \mathrm{h}_{\mathrm{mi}}^{2}=$ maternal genetic heritability for age class $\mathrm{i} ; \mathrm{r}_{\text {mij }}=$ maternal genetic correlation between age classes $\mathrm{i}$ and $\mathrm{j} ; \mathrm{r}_{\text {aimi }}=$ direct-maternal genetic correlation for class $\mathrm{i} ; \mathrm{r}_{\text {aimj }}=$ direct-maternal genetic correlation for age classes $\mathrm{i}$ and $\mathrm{j}$; $\mathrm{pe}_{\mathrm{i}}^{2}=$ proportion of variance due to maternal permanent environmental effects of ewe for age class $i ; r_{\text {eij }}=$ correlation between environmental effects for age classes $\mathrm{i}$ and $\mathrm{j}$; and $\mathrm{e}_{\mathrm{i}}^{2}=$ proportion of variance due to residual effects for age class $\mathrm{i}$. 
averaging -.24 for young, .05 for middle, and .07 for older age of dam classes.

The estimates of genetic correlations between direct genetic and maternal genetic effects for pairs of different age classes varied among breeds, age groups, and traits (Table 3). Any explanation of these estimates would seem to be difficult in a biological sense. Average estimates of genetic correlations between direct and maternal genetic effects across age of dam classes were mostly positive for BWT (averaging .30), were mostly near zero for WWT (averaging .02), and were more variable for ADG (averaging .16).

In general, estimates of the fraction of variance due to permanent environmental effects of dam for BWT were greater than for ADG and WWT. The estimates of proportion of variance due to permanent environmental effects of dams ranged from low to moderately high, indicating that this effect is necessary in models used to estimate genetic parameters or for genetic evaluations. For all traits for young age of dam classes for Rambouillet, the environmental variance went to the maternal permanent environmental component of variance. For that breed and age class, heritability estimates were large, especially for WWT and ADG. Estimates of environmental correlations due to permanent environmental effects of dam across age classes were generally small (Table 3, rows for $r_{e}$ ) after combining the variances due to maternal permanent environmental and residual effects.

\section{Implications}

Genetic expression of early weight traits may depend on the age of the animal's dam. The expression of maternal genetic effects does not seem highly correlated across ages of dams. Heritabilities as a measure of genetic variation seem greatest for an environment defined as a young dam. Taken together, this indicates that genetic evaluations for weaning weight, average daily gain from birth to weaning, and especially birth weight, should consider age of dam as part of the trait. Genetic expression when the dam is young seems to be a different trait from genetic expression with dams of middle and older ages. The variation from breed to breed and from age of dam class to age of dam class indicates that the data that have been evaluated are not sufficient to confirm this tentative conclusion. Therefore, further analyses of weight traits for genetic expression with dams of different ages seems warranted to determine whether there are differences from breed to breed for a genetic $x$ age of dam interaction.

\section{Literature Cited}

Al-Shorepy, S. L., and D. R. Notter. 1995. Heritabilities and genetic correlations of body weight, testis growth and ewe lamb reproductive traits in crossbred sheep. Anim. Prod. 60:185-195.

Al-Shorepy, S. A., and D. R. Notter. 1996. Genetic variation and covariation for ewe reproduction, lamb growth, and lamb scrotal circumference in a fall-lambing sheep flock. J . Anim. Sci. 74: 1490-1498.

Boldman, K. G., L. A. Kriese, S. D. Kachman, and L. D. Van Vleck. 1993. A manual for the use of MTDFREML. ARS, USDA, Clay Center, NE.

Buttazzoni, L., and I. L. Mao. 1989. Genetic parameters of estimated net energy efficiencies for milk production, and body weight change in dairy cows. J. Dairy Sci. 72:671-677.

Ercanbrack, S. K., and A. D. Knight. 1998. Responses to various selection protocols for lamb production in Rambouillet, Targhee, Columbia, and Polypay sheep. J. Anim. Sci. 76: 1311-1325.

Falconer, D. S. 1952. The problem of environment and selection. Am. Nat. 86:293-298.

Fogarty, N. M. 1995. Genetic parameters for live weight, fat and muscle measurements, wool production and reproduction in sheep: A review. Anim. Breed. Abstr. 63:101-143.

Graser, H.-U., S. P. Smith, and B. Tier. 1987. A derivative-free approach for estimating variance components in animal models by restricted maximum likelihood. J . Anim. Sci. 64:1362-1370.

Keeton, L. L., R. D. Green, B. L. Golden, and K. J . Anderson. 1996. Estimation of variance components and prediction of breeding values for scrotal circumference and weaning weight in Limousin cattle. J. Anim. Sci. 74:31-36.

Lin, Y. C., and A. J . Lee. 1986. Sequential estimation of genetic and phenotypic parameters in multivariate mixed model analyses. J. Dairy Sci. 69:2696-2703.

Maria, G. A., K. G. Boldman, and L. D. Van Vleck. 1993. Estimates of variances due to direct and maternal effects for growth traits of Romanov sheep. J. Anim. Sci. 71:845-849.

Näsholm, A., and O. Danell. 1996. Genetic relationships of lamb weight, maternal ability, and mature ewe weight in Swedish finewool sheep. J. Anim. Sci. 74:329-339.

Notter, D. R. 1998. Genetic parameters for growth traits in Suffolk and Polypay sheep. Livest. Prod. Sci. 55:205-213.

Notter, D. R., and J . D. Hough. 1997. Genetic parameter estimates for growth and fleece characteristics in Targhee sheep. J . Anim. Sci. 75:1729-1737.

Okut, H., C. M. Bromley, L. D. Van Vleck, and G. D. Snowder. 1999a. Genotypic expression at different ages: I. Prolificacy traits of sheep. J. Anim. Sci. 77:2357-2365.

Okut, H., C. M. Bromley, L. D. Van Vleck, and G. D. Snowder. 1999b. Genotypic expression at different ages: II. Wool traits of sheep. J. Anim. Sci. 77:2366-2371.

Robertson, A. 1959. The sampling variance of the genetic correlation coefficient. Biometrics 15:469-485.

Satoh, M., A. Nishida, J A.M. van Arendonk, and T. van der Lende. 1997. Benefit of multiple trait selection to increase reproductive traits: Experimental evidence from golden hamsters. J. Anim. Sci. 75:3103-3113.

Smith, S. P., and H.-U. Graser. 1986. Estimating variance compo nents in a class of mixed models by restricted maximum likelihood. J. Dairy Sci. 69:1156-1165.

Tosh, J . J ., and R. A. Kemp. 1994. Estimation of variance components for lamb weights in three sheep populations. J. Anim. Sci. 72:1184-1190.

van Zyl, C. M. 1998. Genetic parameters of growth, reproduction and wool traits in Columbia, Polypay, Rambouillet and Targhee breeds. In: Ph.D. dissertation. Univ. of Nebraska, Lincoln. 